Plasma lipid peroxides in coronary heart disease. Int $\mathbf{f}$ Clin Pharmacol Ther Toxicol 1992;30:77-80.

4 Harats D, Ben-Naim M, Dabach Y, Hollander G, Havivi E, Stein O, et al. Effect of Vitamin C and E supplementation on susceptibility of plasma lipoproteins to peroxidation induced by acute smoking. Atherosclerosis 1990;85:47-54.

5 Nowak D, Ruta U, Piascecka G. Nicotine increases human polymorphonuclear leukocytes chemotactic response-a possible additional mechanism of lung injury in cigarette smokers. Exp Pathol 1990;39:37-43.

6 Hoidal JR, Fox RB, LeMarbe PA, Perri R, Repine JE. Altered oxidative metabolic responses in vitro of alveolar macro- phages from asymptomatic cigarette smokers. Am Rev Respir Dis 1991;123:85-9.

7 Carp H, Miller F, Hoidal JR, Jaroff A. Potential mechanism of emphysema: alpha proteinase inhibitor recovered from lung of cigarette smokers contains oxidised methionine lungs of cigarette smokers contains oxidised methionine and has a decreased elastase inhibitory capacity. Proc Nat

8 Toth KM, Berger EM, Beehler CJ, Repine JE. Erythrocytes from cigarette smokers contain more glutathione and catalase and protect endothelial cells from hydrogen peroxide better than do erythrocytes from non-smokers. $A m$ Rev Respir Dis 1986;134:281-4.

\title{
Acquired protein $S$ deficiency in a patient with systemic lupus erythematosus causing central retinal vein thrombosis
}

\author{
H M Prince, P J Thurlow, R C Buchanan, K M A Ibrahim, P J Neeson
}

\section{Department of \\ Haematology, \\ Austin Hospital, \\ Heidelberg, \\ Victoria, Australia \\ H M Prince \\ P J Thurlow \\ P J Neeson}

Department of

Medicine

R C Buchanan

Department of

Haematology,

Repatriation General

Hospital,

Heidelberg, Victoria,

Australia

K M A Ibrahim

Correspondence to:

Dr H M Prince,

ABMT Program,

Toronto Hospital,

General Division,

200 Elizabeth Street,

mlw 2-036,

Toronto M5G 2C4,

Ontario, Canada.

Accepted for publication

25 August 1994

\begin{abstract}
A 16 year old girl with systemic lupus erythematosus (SLE) developed the rare complication of central retinal vein occlusion. Although classically a disease of older patients, it has been recognised in association with SLE but only in the presence of the lupus anticoagulant or antiphospholipid antibodies. The thrombosis occurred when free protein $S$ concentrations were transiently reduced and there was no family history or other known causes of reduced protein $S$ concentrations. No other prothrombotic risk factors were present.

(f Clin Pathol 1995;48:387-389)
\end{abstract}

Keywords: Protein S, systemic lupus erythematosus, central retinal vein thrombosis.

Central retinal vein occlusion (CRVO) is typically a disease of older patients, rarely occurring before the third decade $^{1}$ and is associated with either an underlying vascular disease or a procoagulant state. Hypertension, diabetes, vasculitides, and hyperlipidaemia are the most commonly associated vascular disorders while the recognised procoagulant states include thrombocytosis, polycythaemia, macroglobulinaemia, the oral contraceptive pill, or systemic lupus erythematosus (SLE). The latter, however, has only been associated with CRVO in the presence of the lupus anticoagulant (LAC) and/or antiphospholipid antibodies (APLA). ${ }^{2}$

LAC/APLA are associated with the increased thrombogenic potential of SLE but other factors have been implicated including abnormalities of the fibrinolytic system, factor VIII complex modifications, increased Von Wil- lebrand factor activity, acquired protein $\mathrm{C}$ deficiency, antithrombin III deficiency, and acquired prostoglandin $\mathrm{I}_{2}$ deficiency. More recently, the laboratory inter-relation between SLE, protein $S$ and $C 4 b$ binding protein (C4BP) has been recognised. ${ }^{3-6}$ However, this relation has not yet translated into a predictable increase in clinical thrombotic risk. Here, we present the case of a young patient with SLE, in whom LAC/APLA were absent but transiently low protein $S$ concentrations led to a predisposition to the development of a thrombosis of her central retinal vein.

\section{Case report}

A 16 year old, previously well, Malaysian girl presented five months earlier with immune thrombocytopenia and SLE. She was not taking any medication. The findings on examination were unremarkable with the exception of a malar rash and lower limb petechiae. A full blood count revealed a haemoglobin of $121 \mathrm{~g} / \mathrm{l}$, a total white cell count of $5 \cdot 8 \times 10^{9} / 1$ with a normal differential count and a platelet count of $5 \times 10^{9} / 1$. Her bone marrow was normocellular with adequate megakaryopoiesis. Normal investigation findings included Epstein-Barr virus and human immunodeficiency virus (HIV) serology, protein electrophoresis, and renal and liver function. Coagulation profile was normal including an activated partial thromboplastin time (APTT) of 36 seconds (normal 25-40). Antinuclear antibodies (ANA) were present in a speckled and nucleolar pattern with a titre of 1 in 10240 . Anti-Ro (SS-A) and anti-LA (SS-B) were demonstrated and antiDNA was $160 \mathrm{IU} / \mathrm{ml}$ (normal <4 IU/ml). Her thrombocytopenia responded to prednisolone $75 \mathrm{mg} /$ day, but she relapsed shortly afterwards 
- Protein S (total) $\mathrm{N}=52-120 \%$

- Protein S (free) $\quad N=50-130 \%$

o C4BP $\mathrm{N}=280-340 \mathrm{mg} / \mathrm{l}$

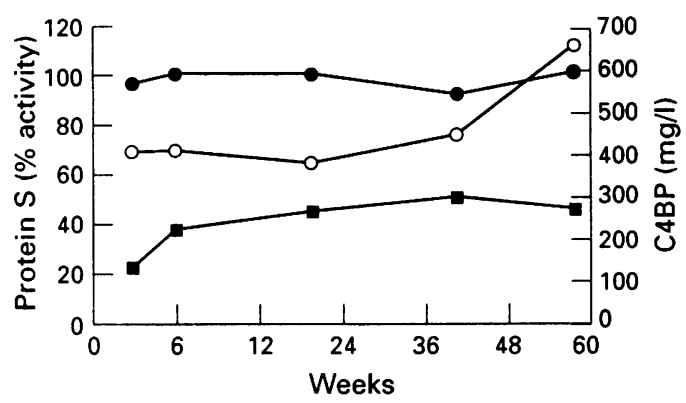

Patient protein $S$ (total and free) and C4BP concentrations from the time of developing CRVO.

during dose reduction but was eventually controlled on $5 \mathrm{mg}$ of prednisolone daily.

One month later, the patient re-presented with symptoms of "shadows" in the right visual field of her right eye and ophthalmological and fluoroscein angiographic findings confirmed non-ischaemic CRVO. The full blood count was normal and procoagulant investigations were undertaken. The LAC was excluded with a normal APTT, Russell Viper Venom time, thromboplastin inhibition time, and platelet neutralisation procedure. Furthermore, when dilutional assays of factors VIII, IX and X were plotted and compared with pooled normal plasma, these lines were parallel excluding the presence of an inhibitor to these factors. Enzyme linked immunosorbent assays (ELISA) for IgG, IgM and IgA APLA were negative. Antigenic (laurell rocket immunoelectrophoresis) and functional protein $\mathrm{C}$ assays (chromogenic and clot methods) were normal, as were the antigenic and functional antithrombin III levels, heparin cofactor II, euglobulin clot lysis time, tissue plasminogen activator, and plasminogen activator inhibitor. Antigenic assay (laurell rocket immunoelectrophoresis) for total protein $\mathrm{S}$ was normal at $97 \%$ (normal $50-150 \%$ ) but free protein $S$ assay, performed by polyethylene glycol precipitation of bound protein $S$ followed by laurell immunoelectrophoresis, displayed a marked initial reduction at $24 \%$ (normal $50-130 \%$ ). A second sample drawn three days later confirmed these assay results. There was a progressive increase in the free protein $S$ concentration over the next eight months, eventually reaching the low normal range $(52 \%)$ (figure). Functional protein S studies were also performed (clot and chromogenic assays) with similar results observed. Total and free protein $S$ concentrations of the patient's parents and only sibling were normal on two separate occasions as were the assays for activated protein $C$ resistance. At the time of thrombosis, the C4BP assay (The Binding Site) showed a significant elevation at $410 \mathrm{mg} / 1$ (normal $280-340 \mathrm{mg} / \mathrm{l}$ ) and this was also followed over the ensuing eight months (figure).

To investigate for the presence of a protein $S$ inhibitor, serial dilutions of the patient's plasma were added to pooled normal plasma and free and total protein $S$ concentrations determined as described above. No accelerated reduction in normal plasma protein $S$ concentrations was evident. Similarly, to investigate for the presence of an abnormal or reduced third component (C-3) (see discussion), serial dilutions of pooled normal plasma were added to the patient's plasma and also to a control sample from a patient with congenital protein $S$ deficiency $(25 \%)$. As normal pooled plasma was added with increasing concentration, the protein $S$ concentrations progressively increased in both patient and control samples but with no significant differences between the two. At the time of thrombosis, the ANA titre was 1 in 2560 and anti-DNA antibodies $80 \mathrm{IU} / 1$. Complement levels remained normal throughout the patient's illness. Prednisolone therapy was increased to $15 \mathrm{mg}$ daily and later reduced to $5 \mathrm{mg}$ and aspirin $150 \mathrm{mg}$ daily was added. There was progressive resolution of the CRVO over the next month and the patient remains clinically stable some eight months after presentation.

\section{Discussion}

Congenital protein $\mathrm{S}$ deficiency, low concentrations of protein $S$ in association with LAC/APLA or autoimmune protein $S$ antibodies increase thrombotic risk. ${ }^{478}$ Furthermore, congenital protein $\mathrm{S}$ deficiency is a major predisposing factor for retinal vascular and cerebral sinus thrombosis including CRVO, central retinal artery occlusion and dural sinus thrombosis. ${ }^{9}$ However, low protein $S$ concentrations are also detected in association with pregnancy, the oral contraceptive pill, nephrotic syndrome, disseminated intravascular coagulation, vitamin $\mathrm{K}$ deficiency, liver disease, and HIV infection but an increased prothrombotic tendency does not clearly exist in these settings. ${ }^{10}$ In the absence of the above factors we investigated the role played by active SLE, low free protein $S$ and elevated C4BP concentrations in predisposing our patient to the development of a CRVO at such an unusually young age.

Protein $S$ exists in two forms, free (38-40\%) and bound $(60-62 \%)$. In the bound form it is non-functional and binds reversibly to C4BP. The free form functions as a protein $\mathrm{C}$ cofactor and plays an important antithrombotic role. C4BP not only binds protein $S$ via its single $\beta$ chain, but also independently regulates complement activation via its seven $\alpha$ chains by accelerating the decay of the classical pathway enzyme C-3 convertase. ${ }^{346}$ As there is a 1 to 1 stoichiometric relation between protein $S$ and $\beta$ chain C4BP, when the latter rises there should also be a subsequent increase in protein $S$ binding with a resultant reduction in free protein $S$ concentrations. ${ }^{3-5} \mathrm{C} 4 \mathrm{BP}$ concentrations increase with acute inflammation such as $\mathrm{SLE}^{46}$ but this concentration can vary depending on the coexistence of a LAC. ${ }^{57}$ It has been suggested that a reduction in free protein $S$ concentrations through this mechanism could result in an increased risk of thrombosis. ${ }^{6} \mathrm{Al}-$ though this postulate has been supported by in 
vivo primate models, ${ }^{10}$ not all studies support it and some have found contradictory evidence. ${ }^{71}$ Similarly, our initial results would concur with the scenario of C4BP elevation being the primary initiating event followed by binding of protein $S$ resulting in a reduction in free protein $S$, however, the progressive increase in C4BP in conjunction with the normalisation of free protein $S$ concentrations cannot be explained by this postulate alone. It appears that, with time, a proportion of the patient's C4BP was incapable of binding protein $S$. A possible explanation is that there was an initial increase predominantly in C4BP $\beta$ chain concentrations followed by a relative increase in C4BP $\alpha$ chain concentrations, which would be incapable of binding protein $S .{ }^{346}$

An autoimmune anti-protein $S$ antibody has been recongised and is associated with a prothrombotic state ${ }^{8}$ but this antibody was directed against both free and bound protein $S$ resulting in noticeably reduced concentrations of both forms of circulating protein S. In our patient there was a reduction in free protein $\mathrm{S}$ concentrations only, thus if an antibody was involved it would have to be directed against an epitope that was exposed only when protein $S$ was not bound to C4BP. Furthermore, in the mixing studies, the addition of an antibody in the patient's plasma to the pooled normal plasma should have resulted in a reduction in free protein $S$ concentrations, which did not occur. Similarly, if C-3, which normally assists protein S/C4BP binding, ${ }^{3}$ was deficient or abnormal, normalisation of the free protein $S$ concentrations should have occurred rapidly in the mixing studies as $\mathrm{C}-3$ was provided by the pooled normal plasma. An association between thromboembolism and corticosteroid therapy has been suggested ${ }^{12}$ but the correlation may be more closely related to the disorder for which the treatment is required and therefore the contribution of steroid therapy to the development of thrombosis is difficult to delineate precisely. Although hormonal effects as well as danazol can influence protein $S$ and C4BP concentrations $^{1011}$ this has not previously been the case with prednisolone. ${ }^{7}$

The treatment of our patient was effective in controlling symptoms and preserving central retinal vein patency. Immunosuppressive and danazol therapy have been attempted with somewhat paradoxical changes in protein $S$ and C4BP concentrations. ${ }^{11}$ Given the young age of our patient for developing a CRVO, the absence of a LAC, APLA (although occasionally thromboses may precede the appearance of APLA), anti-protein S antibody and abnormal $\mathrm{C} 3$, the high C4BP concentrations at diagnosis was probably the initiating event followed by the reduction in free protein $S$ concentrations leading to thrombus formation. The failure of C4BP to normalise in tandem with the free protein $S$ concentrations was atypical of the previous in vitro findings of other investigators ${ }^{3-610}$ but this lack of clinical correlation with the in vitro data dealing with protein $S$ and C4BP concentrations in SLE has been recognised elsewhere. ${ }^{711}$ Further recognition of the interrelation between SLE, C4BP, protein S, and thrombosis should lead to a better understanding of the clinical relation between SLE and thrombotic events.

1 Kohner EM, Cappin JM. Do medical conditions have an influence on central retinal vein occlusions? Proc $R$ Soc Med 1974;67:1052-4

2 Syners B, Lambert M, Hardy J. Retinal and choroidal vaso-occlusive disease in systemic lupus erythematosus associated with antiphospholipid antibodies. Retina 1990 10:255-60.

3 Dahlback B. Protein S and C4b-binding protein: components involved in the regulation of the protein $\mathrm{C}$ an ticoagulant system. Thromb Haemost 1991;66:49-61.

4 Griffin JH, Gruber A, Fernandez JA. Reevaluation of total, free and bound protein $S$ and $\mathrm{C} 4 \mathrm{~b}$-binding protein levels in plasma anticoagulated with citrate and hirudin. Blood 1992;79:3203-11.

5 Keeling DM, Campbell SJ, Mackie IJ, Isenberg DA. Total and free protein $\mathrm{S}$ in systemic lupus erythematosus. Thromb Res 1990;60:237-40.

6 Barnum SR, Dahlback B. C4b-binding protein, a regulatory component of the classical pathway of complement, is an acute-phase protein and is elevated in systemic lupus erythematosus. Complement Inflamm 1990;71:71-7.

7 Ruiz-Arguelles GJ, Ruiz-Arguelles A, Alarcon-Segovia D, Drenkard C, Villa A, Cabiedes J, et al. Natural anticoagulants in systemic lupus erythematosus. Deficiency of protein $\mathrm{S}$ and $\mathrm{C} 4 \mathrm{bp}$ associates with recent history of venous thromboses, antiphospholipid antibodies, and the venous thromboses, antiphospholipid antibodies, and the

8 D'Angelo A, Della Valle P, Crippa L, Pattarini E, Grimaldi LME, D'Angelo SV. Autoimmune protein S deficiency in a bey with severe thromboembolic disease. Blood 1993; 328:1753-7.

9 Vine $\mathrm{AD}$, Meyer MS. The role of abnormalities in the anticoagulant and fibrinolytic systems in retinal vascular occlusions. Surv Ophthalmol 1993;4:283-92.

10 Taylor FB, Esmon CT, Chang A. A primate model of deep vein thrombosis induced by inflammatory mediators. Circulation 1990;82(Suppl 3):770.

11 Thorisdottir H, Evans JA, Schwarz HJ, Comp P, Haluschak $\mathrm{J}$, Ratnoff OD. Some clotting factors in plasma during danazol therapy: free and total protein $S$, but not $C 4 \mathrm{~b}-$ binding protein, are elevated by danazol therapy. $f$ Lab Clin Med 1992;119:698-701.

12 Cosgriff SW. Thromboembolic complications associated with ACTH and cortisone therapy. $\mathscr{f} A M A$ 1951;3:924-6. 